\title{
PENGARUH MOTIVASI INSTRINSIK DAN MOTIVASI EKSTRINSIK TERHADAP KEPUASAN KERJA KARYAWAN DI BANK MUAMALAT INDONESIA CABANG DENPASAR
}

\author{
Kurniawati $^{1}$, Ely Mansur ${ }^{2}$, Jannatun Adhenin ${ }^{3}$ \\ ${ }^{1,2,3}$ Program Studi Ekonomi Syariah, Sekolah Tinggi Agama Islam Denpasar Bali, \\ Indonesia
}

e-mail: \{kurniawati.aam,elymansur1973,jannatunadhenin $\} @$ gmail.com

\begin{abstract}
ABSTRAK
Masalah yang pertama apakah ada pengaruh motivasi intrinsik terhadap kepuasan kerja karyawan, yang kedua apakah ada pengaruh motivasi ekstrinsik terhadap kepuasan kerja karyawan, dan yang ketiga apakah ada pengaruh motivasi instrisik dan motivasi ekstrinsik terhadap kepuasan kerja karyawan di Bank Muamalat Indonesia Cabang Denpasar. Berdasarkan rumusan masalah diatas, maka tujuan dari penelitian ini adalah yang pertama untuk mengetahui pengaruh motivasi instrinsik terhadap kepuasan kerja karyawan, untuk mengetahui pengaruh motivasi ekstrinsik terhadap kepuasan kerja karyawan, dan untuk mengetahui pengaruh motivasi instrinsik dan motivasi ekstrinsik terhadap kepuasan kerja karyawan di Bank Muamalat Indonesia Cabang Denpasar. Penelitian ini merupakan jenis penelitian kuantitatif, teknik pengambilan sampel yang digunakan adalah dengan metode sensus. Hasil penelitian yang didapatkan adalah yang pertama motivasi instrinsik berpengaruh cukup positif dan signifikan terhadap kepuasan kerja karyawan, yang kedua motivasi ekstrinsik berpengaruh positif sangat rendah dan signifikan terhadap kepuasan kerja karyawan, dan yang ketiga motivasi instrinsik dan ekstrinsik berpengaruh positif dan signifikan terhadap kepuasan kerja karyawan di Bank Muamalat Indonesia Cabang Denpasar. Berdasarkan hasil dari penelitian ini motivasi instrinsik dan motivasi ekstrinsik dapat menjelaskan faktor-faktor yang mempengaruhi kepuasan kerja karyawan khususnya di Bank Muamalat indonesia Cabang Denpasar.
\end{abstract}

Kata kunci: Motivasi Instrinsik, Motivasi Ekstrinsik, dan Kepuasan Kerja

\begin{abstract}
The first problem is whether there is an influence of intrinsic motivation on employee job satisfaction, the second is there an influence of extrinsic motivation on employee job satisfaction, and the third is there an influence of intrinsic motivation and extrinsic motivation on employee job satisfaction at Bank Muamalat Indonesia Denpasar Branch. Based on the problem formulation above, the purpose of this study is to first determine the effect of intrinsic motivation on employee job satisfaction, to determine the effect of extrinsic motivation on employee job satisfaction, and to determine the effect of intrinsic motivation and extrinsic motivation on employee job satisfaction at Bank Muamalat Indonesia Denpasar branch. This research is a type of quantitative research, the sampling technique used is the census method. The results obtained are the first intrinsic motivation quite positive and significant effect on employee job satisfaction, the second extrinsic motivation has a very low positive and significant effect on employee job satisfaction, and the third intrinsic and extrinsic motivation have a positive and significant effect on employee job satisfaction in Bank Muamalat Indonesia Denpasar Branch. Based on the results of this study intrinsic motivation and extrinsic motivation can explain the factors that affect employee job satisfaction, especially at Muamalat Indonesia Bank Denpasar Branch.
\end{abstract}

Keywords: Intrinsic Motivation, Extrinsic Motivation, and Job Satisfaction

\section{PENDAHULUAN}

Manusia merupakan salah satu sumber daya perusahaan yang mempunyai peran penting dalam pengelolaan perusahaan dan penggunaan sumber daya lain yang ada di dalam perusahaan. Sistem pengelolaan sumber daya manusia yang tepat merupakan kunci keberhasilan perusahaan untuk mencapai tujuan. Oleh karena itu agar tujuan dan sasaran perusahaan dapat dicapai, perlu adanya 
perhatian yang lebih dari perusahaan terhadap motivasi karyawan dalam memperoleh kesejahteraan.

Sasaran organisasi dapat tercapai apabila perusahaan memperhatikan motivasi yang ada pada karyawannya. Karyawan yang mengetahui motivasi yang baik akan mendorong usahanya lebih giat dan cenderung meningkatkan produktivitas kerja yang ada dalam perusahaan. Motivasi merupakan suatu faktor yang mendorong seseorang untuk melakukan suatu aktivitas tertentu. Motivasi dibagi menjadi dua yaitu motivasi instrinsik dan motivasi ekstrinsik.

Menurut Herzberg dalam Juliansyah Noor, Motivasi instrinsik adalah motivasi yang mendorong seseorang untuk berprestasi yang bersumber dari dalam diri individu tersebut, yang lebih dikenal dengan faktor motivasional. Sedangkan motivasi ekstrinsik adalah motivasi yang bersumber dari luar diri yang turut menentukan perilaku seseorang dalam kehidupannya. ${ }^{1}$

Motivasi berasal dari bahasa Latin yaitu movere yang berarti bergerak atau menggerakkan. Dengan demikian, motivasi berarti suatu kondisi yang menggerakkan atau menjadi sebab seseorang melakukan, suatu perbuatan/kegiatan, yang berlangsung secara sadar. Juga sebagai suatu kekuatan sumber daya yang menggerakkan dan mengendalikan perilaku manusia. $^{2}$

Newstrom mendefinsikan motivasi sebagai "... the processes that account for individual's intensity, direction, and persistence of effort toward attaining goal." Motivasi adalah proses yang memperhitungkan intensitas, arah, dan kegigihan upaya individu untuk mencapai tujuan organisasi. ${ }^{3}$ Menurut Robbins, motivasi adalah suatu kerelaan berusaha seoptimal mungkin dalam pencapaian tujuan perusahaan yang dipengaruhi oleh kemampuan usaha memuaskan beberapa kebutuhan individu. ${ }^{4}$

1 Juliansyah Noor, penelitian ilmu manajemen, (Jakarta) Kencana Pernada Media Group, 2013, h. 236

${ }^{2}$ Ibid, h. 226.

${ }^{3}$ Ibid., h, 227.

${ }^{4}$ Edy Sutrisno, Manajemen sumber daya manusia (jakarta) Prenada Media Group, (2009), h, 111
Herzberg dalam Mullins menyatakan bahwa, "the motivation hygiene theory has extended Maslow's hierarchy of need theory and is more directly applicable to the work situation." ada sekelompok faktor, motivator (faktor intrinsik) yang mendorong seseorang untuk berusaha mencapai kepuasan dan faktor hygiene menimbulkan ketidakpuasan kerja. Dua faktor ini disebutnya faktor hygiene (faktor ekstrinsik) dan faktor motivator. Faktor hygiene memotivasi seseorang untuk keluar dari ketidakpuasan, termasuk didalamnya adalah hubungan antar manusia, imbalan, kondisi lingkungan, dan sebagainya (faktor ekstrinsik), sedangkan faktor motivator memotivasi seseorang untuk berusaha mencapai kepuasan, yang termasuk didalamnya adalah achievement, pengakuan, kemajuan tingkat kehidupan (faktor intrinsik). ${ }^{5}$

Salah satu sasaran penting manajemen sumber daya manusia dalam perusahaan yaitu terciptanya kepuasan kerja karyawan, yang diharapkan agar meningkatkan prestasi kerja. Dengan kepuasan kerja diharapkan pencapaian tujuan perusahaan akan lebih baik dan akurat. Untuk itu sangat penting bagi perusahaan untuk memberikan faktor-faktor pendorong kepuasan kerja, yaitu motivasi instrinsik dan motivasi ekstrinsik.

Menurut Permana dalam Nawawi memberikan pendapat bahwa motivasi instrinsik adalah pendorong kerja yang bersumber dari dalam diri pekerja sebagai individu, berupa kesadaran mengenai pentingnya pekerjaan yang dilaksanakan. ${ }^{6}$ Sedangkan menurut Siagian motivasi instrinsik bersumber dari dalam individu. Motivasi ini menghasilkan integritas dari tujuan-tujuan, baik tujuan organisasi maupun tujuan individu dimana keduanya dapat terpuaskan. ${ }^{7}$

Motivasi ekstrinsik menurut Manullang dinyatakan bahwa jika perusahaan menyediakan kondisi-kondisi kerja, upah, tunjangan, atau keselamatan kerja yang tidak mencukupi, maka ia akan mendapat kesulitan

5 Juliansyah Noor, penelitian ilmu manajemen, (Jakarta) Kencana Pernada Media Group,(2013), h, 235, 236.

6 Hadari, Nawawi, dan Mimi Martini, Penelitian Terapan, Yogyakarta, Gajah Mada University Press, 2009, h. 16

7 Sondang P Siagian, Teori Motivasi Dan Aplikasinya, Jakarta, Rineka Cipta, 2004, h. 76 
dalam menarik karyawan-karyawan yang baik dan perputaran serta kemangkiran yang meningkat. ${ }^{8}$

$$
\text { Para karyawan dituntut oleh }
$$
perusahaan untuk memiliki keterampilan, pengetahuan, dan kemampuan yang cukup untuk bekerja sesuai dengan standar yang ditetapkan. Namun permasalahan yang muncul terletak pada bagaimana mempertahankan karyawan untuk tetap dapat bekerja sesuai dengan tuntutan yang ada, dan selalu bersemangat dalam setiap pekerjaannya, sehingga kepuasan kerja karyawan dapat tercapai.

Robbins mengemukakan bahwa kepuasan kerja merujuk ada sikap umum individu terhadap pekerjaannya. Menurut Baron dan Greenberg dalam Noermijati, bahwa kepuasan kepuasan kerja melibatkan sikap positif dan negatif individu terhadap pekerjaan. ${ }^{9}$ Handoko juga mengemukakan kepuasan kerja adalah keadaan emosional yang menyenangkan atau tidak menyenangkan bagi para karyawan memandang pekerjaan mereka. ${ }^{10}$

Lopopolo juga berpendapat bahwa kepuasan kerja merupakan konstruk yang komplek dan seringkali diukur sebagai sikap global dari seorang pegawai terhadap pekerjaannya. ${ }^{11}$

Wexley dan yukl mengartikan kepuasan kerja sebagai, "the way an employee feels abiout his or her job." Artinya, Bahwa kepuasan kerja adalah cara karyawan merasakan dirinya atau pekerjaannya. Dapat disimpulkan bahwa kepuasan kerja adalah perasaan yang menyokong atau tidak menyokong dalam diri karyawan yang berhubungan dengan pekerjaan maupun kondisi dirinya. ${ }^{12}$

8 M. Manullang, Manajemen Sumber Daya Manusia, Yogyakarta, Andi Offset, 2001, h. 195

${ }^{9}$ Noermijati, Aktualisasi Teori Herzberg, Kepuasan Kerja Dan Kinerja Spiritual Manajer Operasional, (Malang: Universitas Brawijawa Press, 2013), h. 36,37

${ }^{10}$ Edy Sutrisno,Manajemen sumber daya manusia (jakarta) Prenada Media Group, (2009), h. 75

${ }_{12}^{11}$ Op. Cit., Noermijati, h.38

12 Juliansyah Noor, penelitian ilmu manajemen, (Jakarta) Kencana Pernada Media Group, 2013, h. 256
Secara garis besar dapat disimpulkan bahwa motivasi mempunyai peran sangat penting bagi para karyawan. Karena dengan motivasi yang tinggi, maka pekerjaan dilakukan dengan semangat dan bergairah, sehingga akan mencapai hasil yang optimal dan kepuasan kerja yang tentunya akan mendukung tercapainya tujuan yang diinginkan dengan efisien dan efektif.motivasi berkaitan dengan kepuasan, dimana kepuasan hanya dapat ditingkatkan dengan motivasi yang tinggi, kemauan dan kemampuan dalam melakukan tugas yang didukung dengan lingkungan kerja yang nyaman.

Hal diatas menujukkan bahwa motivasi instrinsik dan motivasi ekstrinsik merpakan faktor yang dapat mempengaruhi kepuasan kerja karyawan, baik secara sendirisendiri maupun secara simultan.

Adapun rumusan masalah dalam penelitian ini adalah: (1) Apakah ada pengaruh motivasi intrinsik terhadap kepuasan kerja karyawan di Bank Muamalat Indonesia Cabang Denpasar?; (2) Apakah ada pengaruh motivasi ekstrinsik terhadap kepuasan kerja karyawan di Bank Muamalat Indonesia Cabang Denpasar?; dan (3) Apakah ada pengaruh secara simultan antara motivasi instrisik dan motivasi ekstrinsik terhadap kepuasan kerja karyawan di Bank Muamalat Indonesia Cabang Denpasar?

Untuk mendapatkan jawaban dari rumusan masalah diatas maka peneliti melakukan kajian empiris melalui metodologi sebagaimana paparan pada bagian motode dalam penulisan artikel ini.

Tujuan penelitian ini adalah yang pertama untuk mengetahui pengaruh motivasi intrinsik terhadap kepuasan kerja karyawan di Bank Muamalat Indonesia Cabang Denpasar, yang kedua untuk mengetahui pengaruh motivasi ekstrinsik terhadap kepuasan kerja karyawan di Bank Muamalat Indonesia Cabang Denpasar, dan yang ketiga untuk mengetahui pengaruh secara simultan antara motivasi instrisik dan motivasi ekstrinsik terhadap kepuasan kerja karyawan di Bank Muamalat Indonesia Cabang Denpasar.

\section{METODE PENELITIAN}

Penelitian ini menggunakan pendekatan kuantitatif, yaitu penelitian yang menganalisis 
data secara kuantitatif karena data penelitian ini berupa angka-angka dan analisis menggunakan statistik. ${ }^{13}$ Angka-angka tersebut diperoleh melalui penyebaran kuesioner kepada para responden, yakni karyawan Bank Muamalat Indonesia Cabang Denpasar. jenis penelitian ini yaitu menggunakan analisis deskriptif. Analisis deskriptif adalah statistik yang digunakan untuk menganalisa data dengan cara mendeskripsikan atau menggambarkan data yang telah terkumpul sebagaimana adanya tanpa bermaksud membuat kesimpulan yang berlaku untuk umum atau generalisasi. ${ }^{14}$

Populasi pada penelitian ini adalah seluruh karyawan Bank Muamalat Indonesia Cabang Denpasar. Penentuan jenis populasi ini didasarkan atas alasan bahwa yang akan diuji adalah karyawan Bank Muamalat Indomesia Cabang Denpasar yang berjumlah sekitar 29 orang yang terdiri dari 23 permanent staff/ karyawan tetap dan 6 mulia staff/ karyawan kontrak. Sampel dari penelitian ini adalah semua karyawan Bank Muamalat Indonesia Cabang Denpasar sebanyak 29 orang dengan menggunakan teknik sensus. Variabel penelitian terdiri dari; motivasi instrinsik $\left(\mathrm{X}_{1}\right)$, motivasi ekstrinsik $\left(\mathrm{X}_{2}\right)$, dan kepuasan kerja (Y), Pengukuran data penelitian menggunakan kuesioner pola skala likert (ordinal). Pemberian skor jawaban 1-5 adalah untuk mendapatkan data skala interval.

Pengumpulan data penelitian menggunakan kuesioner dan studi dokumentasi. Sumber data penelitian berasal dari lembar jawaban kuesioner responden (karyawan) dan buku-buku, jurnal, dokumen terkait dan sebagainya.

Teknik analisis data meliputi; uji validitas dan reliabilitas data, uji statistik deskriptif, uji asumsi klasik (uji normalitas, uji linieritas, uji multikolinearitas, dan uji heteroskedastisitas), uji hipotesis (uji t dan uji F), dan uji regresi linier berganda. Proses analisis menggunakan SPSS 22 for Windows. Hasil uji validasi dan reliabilitas menunjukkan bahwa instrumen penelitian adalah valid dan reliabel.

${ }^{13}$ Sugiyono, Metode Penelitian Kuantitatif Kualitatif dan R\&D, Bandung: Alfabeta, 2008, h. 7

14 Sugiyono, Metode Penelitian

Kuantitatif, Bandung: Alfabeta, 2018, hal. 226

\section{HASIL DAN PEMBAHASAN}

Nilai mean yang di peroleh masigmasing variabel adalah:

Motivasi Instrinsik (X1)

Dari hasil analisis deskriptif setiap item-item variabel motivasi instrinsik di peroleh raata-rata mean sebesar 3,95 yang berarti responden memberikan respon sangat positif (sangat baik) pada seluruh pernyataan variabel motivasi instrinsik (X1).

\section{Motivasi Ekstrinsik (X2)}

Dari hasil analisis deskriptif setiap item-item variabel motivasi ekstrinsik di peroleh raata-rata mean sebesar 4.07 yang berarti responden memberikan respon sangat positif (sangat baik) pada seluruh pernyataan variabel motivasi ekstrinsik (X2).

Kepuasan Kerja (Y)

Dari hasil analisis deskriptif setiap item-item variabel kepuasan kerja di peroleh raata-rata mean sebesar 3,99 yang berarti responden memberikan respon sangat positif (sangat baik) pada seluruh pernyataan variabel kepuasan kerja (Y)

Hipotesis penelitian ini adalah: (1) terdapat pengaruh yang signifikan dan positif atas variabel motivasi instrinsik terhadap kepuasan kerja karyawan di Bank Muamalat Indonesia Cabang Denpasar; (2) terdapat pengaruh yang signifikan dan positif atas variabel motivasi ekstrinsik terhadap kepuasan kerja karyawan di Bank Muamalat Indonesia Cabang Denpasar; dan (3) terdapat pengaruh secara simultan antara variabel motivasi instrinsik dan variabel ekstrinsik terhadap kepuasan kerja karyawan di Bank Muamalat Indonesia Cabang Denpasar.

Dari hasil pengujian berdasarkan uji validitas dari variabel prestasi kerja, variabel loyalitas karyawan dan variabel promosi jabatan hasilnya adalah pernyataan pada ketiga variabel ini dinyatakan valid dan dapat digunakan dalam penelitian karena nilai $\mathrm{R}$ hitung > R tabel $(0,367)$. 
Tabel 1. Uji Reliabilitas

\begin{tabular}{lcc}
\hline \multicolumn{1}{c}{ Variabel } & $\begin{array}{l}\text { CronbachAlphaBased } \\
\text { onStandardized items }\end{array}$ & Keterangan \\
\hline Motivasi Instrinsik (X1) & 0,942 & Reliabel \\
\hline $\begin{array}{l}\text { Motivasi Ekstrinsik } \\
\text { (X2) }\end{array}$ & 0,931 & Reliabel \\
\hline Kepuasan Kerja (Y) & 0,905 & Reliabel \\
\hline
\end{tabular}

Dari hasil pengujian berdasarkan uji dengan nilai hasil Cronbach alpha yaitu lebih besar dari 0,60 .

reliabilitas maka dapat diketahui bahwa

seluruh variabel penelitian dikatakan reliabel,

Tabel 2 Uji Normalitas Data

\begin{tabular}{|c|c|c|}
\hline \multicolumn{3}{|c|}{ One-Sample Kolmogorov-Smirnov Test } \\
\hline \multicolumn{3}{|c|}{ Unstandardized Residual } \\
\hline $\mathrm{N}$ & & 29 \\
\hline \multirow{2}{*}{$\begin{array}{l}\text { Normal } \\
\text { Parameters }\end{array}$} & Mean & 0,0000000 \\
\hline & Std. Deviation & 0,59542016 \\
\hline \multirow{3}{*}{$\begin{array}{l}\text { Most Extreme } \\
\text { Differences }\end{array}$} & Absolute & 0,241 \\
\hline & Positive & 0,241 \\
\hline & Negative & $-0,141$ \\
\hline \multicolumn{2}{|l|}{ Test Statistic } & 0,241 \\
\hline \multicolumn{2}{|c|}{ Asymp. Sig. (2-tailed) } & $.200^{\mathrm{c}}$ \\
\hline \multicolumn{3}{|c|}{ a. Test distribution is Normal. } \\
\hline \multirow{2}{*}{\multicolumn{3}{|c|}{ b. Calculated from data. }} \\
\hline c. Lilliefors Sig & & \\
\hline
\end{tabular}

Pada uji normalitas data memperoleh nilai signifikansi Asymp. Sig. (2-tailed) sebesar 0,200, dimana nilai tersebut lebih besar dari 0,05. Maka dapat disimpulkan bahwa berdasarkan pengambilan keputusan dalam uji normalitas Kolmogorov- smirnov di atas, data tersebut berdistribusi normal. Dengan demikian, asumsi atau persyaratan uji normalitas telah terpenuhi.

Tabel 3. Uji Linieritas

\begin{tabular}{|c|c|c|c|c|c|c|c|}
\hline \multicolumn{8}{|c|}{ ANOVA Table } \\
\hline & & & $\begin{array}{l}\text { Sum of } \\
\text { Squares }\end{array}$ & df & $\begin{array}{l}\text { Mean } \\
\text { Square }\end{array}$ & $\mathrm{F}$ & Sig. \\
\hline \multirow{5}{*}{$\begin{array}{l}\text { Kepuasan * } \\
\text { M_Intrinsik }\end{array}$} & \multirow{3}{*}{$\begin{array}{l}\text { Between } \\
\text { Groups }\end{array}$} & (Combined) & 827,182 & 10 & 82,718 & 121,380 & 0,000 \\
\hline & & Linearity & 825,463 & 1 & 825,463 & 1211,277 & 0,000 \\
\hline & & $\begin{array}{l}\text { Deviation } \\
\text { from } \\
\text { Linearity }\end{array}$ & 1,719 & 9 & 0,191 & 0,280 & 0,972 \\
\hline & \multicolumn{2}{|c|}{ Within Groups } & 12,267 & 18 & 0,681 & & \\
\hline & \multicolumn{2}{|l|}{ Total } & 839,448 & 28 & & & \\
\hline
\end{tabular}


Dalam uji linieritas nilai sig diperoleh hasil signifikansi 0,972 dimana nilai tersebut lebih besar dari 0,05. Maka dapat disimpulkan bahwa ada hubungan linear secara signifikan antara variabel motivasi intrinsik (X1), motivasi ekstrinsik (X2) dengan variabel kepuasan kerja $(\mathrm{Y})$, sedangkan dalam nilai $\mathrm{F}$ diperoleh nilai $\mathrm{F}$ hitung sebesar 0,681 , dimana $\mathrm{F}$ hitung lebih kecil dari pada $\mathrm{F}$ tabel 2,46. Maka ada hubungan linear antara motivasi intrinsik (X1) dan motivasi eksrinsik (X2) dengan kepuasan pekerja (Y).

Tabel 4. Uji Multikolenieritas

\begin{tabular}{|c|c|c|c|c|c|c|c|}
\hline \multicolumn{8}{|c|}{ Coefficients $^{\mathrm{a}}$} \\
\hline \multirow[t]{2}{*}{ Model } & \multicolumn{2}{|c|}{$\begin{array}{l}\text { Unstandardized } \\
\text { Coefficients }\end{array}$} & \multirow{2}{*}{$\begin{array}{c}\begin{array}{c}\text { Standardized } \\
\text { Coefficients }\end{array} \\
\text { Beta }\end{array}$} & \multirow[t]{2}{*}{$\mathrm{T}$} & \multirow[t]{2}{*}{ Sig. } & \multicolumn{2}{|c|}{ Collinearity Statistics } \\
\hline & B & $\begin{array}{l}\text { Std. } \\
\text { Error }\end{array}$ & & & & Tolerance & VIF \\
\hline 1 (Constant) & 1,406 & 1,004 & & 1,401 & 0,173 & & \\
\hline M_intrinsik & 0,596 & 0,021 & 0,911 & 27,783 & 0,000 & 0,423 & 2,361 \\
\hline M_ekstrinsik & 0,067 & 0,021 & 0,107 & 3,260 & 0,003 & 0,423 & 2,361 \\
\hline a. Dependent Va & e: Kep & & & & & & \\
\hline
\end{tabular}

Dalam uji multikolonieritas nilai sig pada variabel motivasi instrinsik memperoleh angka sebesar 0,890 dan pada variabel motivasi ekstrinsik sebesar 0,423, Angka tersebut menunjukan bahwa nilai tolerance tiap variable lebih dari 0,1 ; sedangkan pada kolom VIF variable X1 dan X2, menghasilkan angka sebesar 2,361 yang mana angka tersebut lebih kecil dari pada 10,00. Maka dapat disimpulkan berdasarkan uji multikolonieritas data tersebut tidak terjadi gejala multikolonieritas. Dalam uji heteroskedastisitas juga tidak terjadi gejala heteroskedastisitas hal ini dapat di lihat pada grafik dibawah ini:

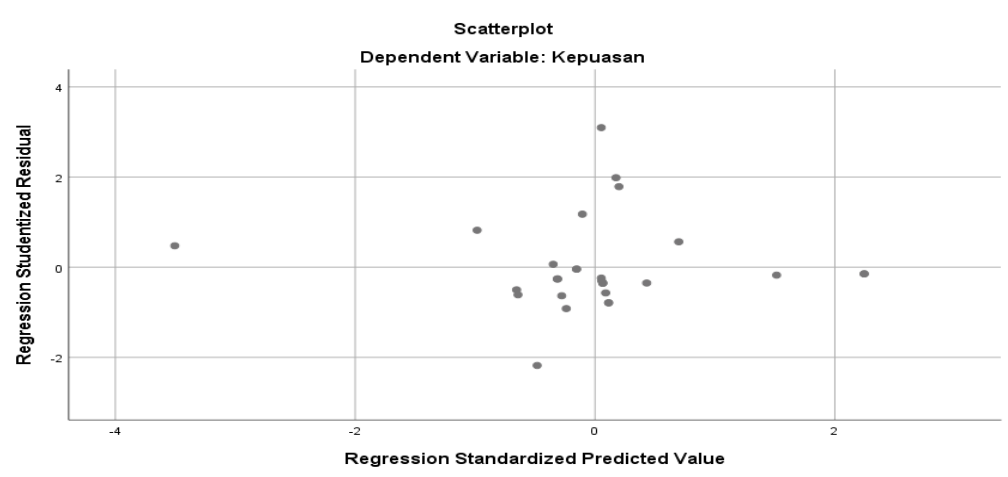

Gambar 1. Grafik uji heteroskedastisitas

Titik hitam pada diagram tersebut tidak ada pola tertentu karena titik meyebar tidak beraturan diatas dan dibawah sumbu 0 pada sumbu Y. Maka dapat disimpulkan tidak terdapat gejala heteroskedastisitas. 
Tabel 5. Uji Parsial (t test)

\begin{tabular}{|c|c|c|c|c|c|c|}
\hline \multicolumn{7}{|c|}{ Coefficients $^{\mathrm{a}}$} \\
\hline \multirow{2}{*}{\multicolumn{2}{|c|}{ Model }} & \multicolumn{2}{|c|}{$\begin{array}{c}\text { Unstandardized } \\
\text { Coefficients }\end{array}$} & \multirow{2}{*}{$\begin{array}{c}\begin{array}{c}\text { Standardized } \\
\text { Coefficients }\end{array} \\
\text { Beta }\end{array}$} & \multirow[t]{2}{*}{$\mathbf{t}$} & \multirow[t]{2}{*}{ Sig. } \\
\hline & & $\mathrm{B}$ & $\begin{array}{l}\text { Std. } \\
\text { Error }\end{array}$ & & & \\
\hline \multirow[t]{3}{*}{1} & (Constant) & 1,406 & 1,004 & & 1,401 & 0,173 \\
\hline & M_intrinsik & 0,596 & 0,021 & 0,911 & 27,783 & 0,000 \\
\hline & M_ekstrinsik & 0,067 & 0,021 & 0,107 & 3,260 & 0,003 \\
\hline
\end{tabular}

a. Dependent Variable: Kepuasan

Pengujian hasil hipotesis pertama terdapat nilai signifikansi (Sig) variable motivasi instrinsik $0,000<$ dari pada probabilitas 0,05 . Nilai $t$ hitung pada variable motivasi instrinsik 27,783 > dari pada t table 2,055. Maka dapat disimpulkan bahwa hipotesis diterima, berarti ada pengaruh motivasi intrinsik dengan kepuasan kerja.
Pengujian hasil hipotesis kedua terdapat nilai signifikansi (Sig) variable motivasi ekstrinsik $0,003<$ dari pada probabilitas 0,05 . Nilai t hitung pada variable motivasi ekstrinsik 3,260 > dari pada t tabel 2,055. Maka dapat disimpulkan bahwa hipotesis diterima berarti ada pengaruh antara motivasi ekstrinsik dengan kepuasan kerja.

Tabel 6. Uji Simultan (f test)

\begin{tabular}{|c|c|c|c|c|c|c|}
\hline \multicolumn{7}{|c|}{ ANOVA $^{a}$} \\
\hline \multicolumn{2}{|c|}{ Model } & $\begin{array}{l}\text { Sum of } \\
\text { Squares }\end{array}$ & Df & $\begin{array}{l}\text { Mean } \\
\text { Square }\end{array}$ & $\mathrm{F}$ & Sig. \\
\hline \multirow[t]{4}{*}{1} & Regressio & 829.522 & 2 & 414.761 & 1086.3 & $.000^{\mathrm{b}}$ \\
\hline & $\mathrm{n}$ & & & & 40 & \\
\hline & Residual & 9.927 & 26 & .382 & & \\
\hline & Total & 839.448 & 28 & & & \\
\hline
\end{tabular}

a. Dependent Variable: y

b. Predictors: (Constant), x2, x1

Pengujian hasil hipotesis ketiga terdapat nilai $\mathrm{F}$ hitung sebesar 1086,340 lebih besar dari $F$ table 3,35 dan nilai sig. menunjukan nilai 0,000 atau lebih kecil dari tingkat signifikansi 0,05 sehingga dapat dikatakan bahwa hipotesis diterima, ada pengaruh antara motivasi intrinsik dan motivasi ekstrinsik terhadap kepuasan bekerja.

Tabel 7. Hasil Uji Regresi Linier Berganda

\begin{tabular}{ccccc}
\hline \multicolumn{5}{c}{ Analisis Regresi Multiples (Berganda) } \\
\hline Variabel & Koefisien Regresi & R & Sig \\
\hline Kodel & & & & \\
\hline 1 & Konstanta & 1.406 & 0,727 & 0.173 \\
\hline X1 & 0.596 & 0,000 \\
\hline X2 & 0.067 & 0,003 \\
\hline Sig Anova: & 0,000 & & \\
\hline F hitung: & 1086.340 & & \\
\hline R Square: & 0,988 & & \\
\hline
\end{tabular}


Uji regresi linier berganda ini digunakan untuk mengukur kekuatan dua variabel atau lebih dan juga menunjukan arah hubungan antara variabel dependen dengan variabel independen. Adapun rumus dari regresi linier berganda (multiple linier regression) secara umum adalah sebagai berikut. $^{15}$

Hasil penelitian menunjukkan Pengaruh Motivasi Instrinsik dan Motivasi Ekstrinsik berpengaruh terhadap Kepuasan Kerja Karyawan baik secara parsial maupun simultan. Hal ini dapat dilihat pada persamaan hasil uji regresi linier berganda terdapat nilai: $\mathrm{Y}=\mathrm{a}+\mathrm{b} 1 \mathrm{X} 1+\mathrm{b} 2 \mathrm{X} 2+\mathrm{e}$ $\mathrm{Y}=1,406+0,596 \mathrm{X} 1+0,067 \mathrm{X} 2+\mathrm{ei}$.

Berdasarkan hasil persamaan regresi dapat dijelaskan pola pengaruh variabel Motivasi Instrinsik (X1) dan Motivasi Instrinsik (X2) terhadap Kepusan Kerja Karyawan (Y) sebagai berikut: (1) Nilai konstan sebesar 1,406 menyatakan bahwa apabila terjadi varibel independen Motivasi Instrinsik (X1) dan Motivasi Ekstrinsik (X2) sama dengan nol, maka variabel dependen Kepuasan Kerja Karyawan (Y) adalah sebesar 1,406; (2) Nilai koefisien $\beta 1=0,596$ menunjukan bahwa terdapat pengaruh positif antara variabel Motivasi Instrinsik (X1), terhadap Kepuasan Kerja karyawan (Y) sebesar 0,596. Hal ini berarti apabila variabel independen Motivasi Instrinsik (X1), naik sebesar 1 satuan dengan asumsi bahwavariabel bebas lainnya konstan, maka variabel terhadap Kepuasn Kerja Karyawan (Y) akan mengalami kenaikan sebesar 0,596 satuan; dan (3) Nilai koefsien $\beta 2=0,067$ menunjukan bahwa terdapat pengaruh positif antara variabel Motivasi Ekstrinsik (X2), terhadap Kepuasan Kerja karyawan (Y) sebesar 0,067. Hal ini berarti apabila variabel independen Motivasi Ekstrinsik (X2), naik sebesar 1 satuan dengan asumsi bahwa variabel bebas lainnya konstan, maka variabel terhadap Kepuasan Kerja Karyawan (Y) akan mengalami kenaikan sebesar 0,067 satuan.

Pengaruh Motivasi Instrinsik terhadap Kepuasan Kerja Karyawan

15 Syofian Siregar,Statistic Parametrik Untuk Penelitian Kuantitatif, Jakarta: Bumi Aksara, 2013. h. 405
Variabel Motivasi Instrinsik (X1) memiliki tingkat signifikan sebesar $0,000<$ 0,05 dan memiliki koefisien positif sebesar 0,596 maka Ho ditolak dan H1 diterima. Selain itu, Motivasi Instrinsik (X1) memiliki thitung lebih besar dari tabel, yaitu sebesar 27,783 > 2,055. Hal ini berarti sesuai dengan H1 yang menyatakan bahwa variabel Motivasi Instrinsik berpengaruh cukup positif dan signifikan terhadap Kepuasan Kerja Karyawan sebesar 0,596 atau $59,6 \%$ dan sisanya dipengaruhi variabel lain.

Hasil Penelitian sejalan dengan penelitian yang dilakukan oleh Fakhrian Harza Maulana tahun 2015 yang berjudul: "Pengaruh Motivasi Instrinsik, Motivasi Ekstrinsik dan Komitmen Organisasi Terhadap Kinerja Kerja Karyawan Pada bank BTN Kantor Cabang Malang." Hasil penelitian ini antara lain untuk meningkatkan kinerja karyawannya salah satunya dengan memotivasi karyawan dan memberikan komitmen kepada karyawan. Secara bersama-sama variabel motivasi instrinsik, motivasi ekstrinsik, dan komitmen organisasi berpengaruh positif dan signifikan terhadap variabel kinerja karyawan. Berdasarkan hasil analisis data dan pengujian hipotesis dengan hasil R sebesar 0,794 (7.94\%) yang berarti antara ketiga variabel bebas mempunyai pengaruh yang cukup kuat, sedangkan R Square sebesar 0,630 (63\%) ketiga variabel bebas berpengaruh terhadap kinerja karyawan, dan sisanya $37 \%$ dipengaruhi oleh Faktor lain yang tidak diteliti. $^{16}$

\section{Pengaruh Motivasi Ekstrinsik terhadap Kepuasan Kerja Karyawan}

Variabel Motivasi Ekstrinsik (X2) memiliki tingkat signifikan sebesar $0,003<$ 0,05 dan memiliki koefisien positif sebesar 0,067 maka Ho ditolak dan $\mathrm{H} 2$ diterima. Selain itu, Motivasi Ekstrinsik (X2) memiliki thitung lebih besar dari tabel yaitu sebesar 3,260 $>2,055$. Hal ini berarti sesuai dengan $\mathrm{H} 2$ yang menyatakan bahwa variabel motivasi

16 Fakhrian Harza Maulana, Pengaruh Motivasi Instrinsik, Motivasi Ektrinsik Dan Komitmen Organisasi Terhadap Kinerja Kerja Karyawan Pada Bank BTN Kantor Cabang Malang, 2015 
ekstrinsik berpengaruh positif sangat rendah dan signifikan terhadap kepuasan kerja karyawan sebesar 0,067 atau $6,7 \%$.

Hal ini sejalan dengan penelitian terdahulu yang sama dengan Motivasi Instrinsik terhadap Kepuasan kerja yang dilakukan oleh Fakhrian Harza Maulana tahun 2015 yang berjudul: "Pengaruh Motivasi Instrinsik, Motivasi Ekstrinsik dan Komitmen Organisasi Terhadap Kinerja Kerja Karyawan Pada bank BTN Kantor Cabang Malang." Hasil penelitian ini antara lain untuk meningkatkan kinerja karyawannya salah satunya dengan memotivasi karywan dan memberikan komitmen kepada karyawan. Secara bersama-sama variabel motivasi instrinsik, motivasi ekstrinsik, dan komitmen organisasi berpengaruh positif dan signifikan terhadap variabel kinerja karyawan. Berdasarkan hasil analisis data dan pengujian hipotesis dengan hasil R sebesar 0,794 (7.94\%) yang berarti antara ketiga variabel bebas mempunyai pengaruh yang cukup kuat, sedangkan R Square sebesar $0,630 \quad(63 \%)$ ketiga variabel bebas berpengaruh terhadap kinerja karyawan, dan sisanya $37 \%$ dipengaruhi oleh Faktor lain yang tidak diteliti. ${ }^{17}$

\section{Pengaruh Motivasi Instrinsik dan Motivasi Ekstrinsik terhadap kepuasan Kerja Karyawa}

Variabel motivasi instrinsik terhadap motivasi ekstrinsik memperoleh nilai Fhitung $>$ Ftabel $(1086,340>3,35)$, dengan taraf signifikan sebesar $0,000<0,05$. Dan memperoleh nilai rsquare sebesar 0,988 yang artinya bahwa proses motivasi instrinsik dan motivasi ekstrinsik berpengaruh positif dan signifikan terhadap kepuasan kerja karyawan.

Hasil Penelitian sejalan dengan penelitian yang dilakukan oleh Sagung Binda Karmita tahun 2015 yang berjudul "Pengaruh Motivasi Kerja dan Penempatan Karyawan terhadap Kepuasan Kerja dan Kinerja Kerja Karyawan Pada Analisis Kredit PT BPD Bali Cabang Utama Denpasar". Hasil penelitian ini menunjukkan bahwa motivasi kerja memiliki pengaruh yang positif dan signifikan terhadap kepuasan kerja. Hasil pengujian hipotesis pertama menunjukkan bahwa pengaruh motivasi kerja terhadap kepuasan menunjukkan nilai koefisien jalur sebesar
0,4695 dengan nilai t-statistik sebesar 4,2167. Nilai $\mathrm{t}$ statistik tersebut lebih besar dari nilai $\mathrm{t}$ tabel sebesar 2,007 yang menunjukkan bahwa ada pengaruh positif dan signifikan dari variabel motivasi kerja terhadap kepuasan. ${ }^{18}$

Berdasarkan hasil perhitungan determinasi $\left(\mathrm{R}^{2}\right)$ sebesar 0,988 yang berarti pengaruh Motivasi Instrinsik dan Motivasi Ekstrinsik berpengaruh terhadap Kepuasan Kerja Karyawan di Bank Muamalat Indonesia Cabang Depasar sebesar 98,8\%. Sedangkan sisanya (100\%-98,8\%) dipengaruhi oleh variabel lain.

Dan terakhir berdasarkan hasil uji normalitas nilai Asymp. Sig. (2-tailed) sebesar $0,200>0,05$ maka dapat disimpulkan bahwa data-data penelitian telah berdistribusi normal.

\section{PENUTUP}

Berdasarkan hasil kajian empiris di atas, peneliti menyimpulkan: (1) Terdapat pengaruh cukup positif dan signifikan motivasi instrinsik terhadap kepuasan kerja karyawan Bank Muamalat Indonesia Cabang Denpasar, hal tersebut ditunjukkan dari hasil uji t hitung sebesar 27,783 dengan signifikansi 0,000 dan nilai koefisien $\beta 1$ sebesar 0,596 atau 59,6\% dan sisanya dipengaruhi variabel lain. Dengan demikian hipotesis satu (H1) yang menyatakan bahwa motivasi instrinsik berpengaruh terhadap kepuasan kerja dapat diterima.; (2) Terdapat pengaruh positif sangat rendah dan signifikan motivasi ekstrinsik terhadap kepuasan kerja karyawan Bank Muamalat Indonesia Cabang Denpasar, hal tersebut ditunjukkan dari hasil uji t hitung sebesar 3,260 dengan signifikansi 0,003 dan nilai koefisien $\beta 2$ sebesar 0,067 atau $6,7 \%$. Dengan demikian hipotesis dua (H2) yang menyatakan bahwa motivasi ekstrinsik berpengaruh terhadap kepuasan kerja dapat diterima. (3) Terdapat pengaruh positif motifasi instrinsik dan motivasi ekstrinsik terhadap kepuasan kerja karyawan Bank Muamalat Indonesia Cabang Denpasar, dari uji $\mathrm{F}$ yang diperoleh diketahui bahwa nilai Fhitung > Ftabel $(1086,340>3,35)$, dengan taraf signifikan sebesar $0,000<0,05$ dan

18 Sagung Binda Karmita, Pengaruh Motivasi Kerja Dan Penempatan Karyawan Terhadap Kepuasan Kerja Dan Kinerja Karyawan Studi Pada Analis Kredit PT. BPD Bali Cabang Utama Denpasar, 2015 
persamaan regresi $\mathrm{Y}=1,406+0,596 \times 1+$ 0,067X2. Dengan demikian hipotesis tiga (H3) yang menyatakan bahwa motifasi instrinsik dan motivasi ekstrinsik berpengaruh terhadap kepuasan kerja dapat diterima. (4) Berdasarkan penelitian ini Motivasi Instrinsik dan Motivasi Ekstrinsik dapat menjelaskan faktor-faktor yang mempengaruhi kepuasan kerja karyawan sebesar rSquare $=0,988$ atau $98,8 \%$. Sedangkan sisanya (100\%-98,8\%) dipengaruhi oleh variabel lain yang tidak diteliti.

Dengan demikian, peneliti menyarankan: (1) bagi perusahaan; untuk bisa memperhatikan faktor-faktor yang mempengaruhi motivasi instrinsik misalnya memperhatikan prestasi karyawan karena prestasi karyawan berdampak besar bagi keberhasilan perusahaan; perusahaan juga harus memperhatikan faktor-faktor yang mempengaruhi motivasi ekstrinsik, karena Motivasi ekstrinsik mempunyai pengaruh yang poisitif sangat rendah terhadap kepuasan kerja, karena banyaknya karyawan Bank Muamalat Indonesia Cabang Denpasar yang mangkir disebabkan kurangnya motivasi eksternal diharapkan kepada Bank Muamalat Indonesia Cabang Denpasar untuk selalu memperhatikan dan memberi pengarahan terhadap karyawan karena masih banyaknya karyawan yang mangkir akibat kurangnya minat bekerja. Untuk mengatasi masalah tersebut perusahaan harus memberi ganjaran yang jelas seperti penghargaan, pujian, pangkat dan sebagainya yang diberi untuk memaksimalkan kepuasan kerja karyawan. Diharapkan juga perusahaan tetap mengutamakan kesejahteraaaan karyawan agar karyawan selalu meningkatkaan kepuasan kerja sehingga memberi keuntungan bagi perusahaan. (2) bagi karyawan; untuk meningkatkan motivasi instrinsik dan motivasi ekstrinsik agar mendapatkan kepuasan kerja dan bisa mengerjakan pekerjaan dengan rasa senang. (3) bagi peneliti mendatang; untuk peneliti selanjutnya dapat mengkaji lebih dalam tentang motivasi instrinsik dan motivasi ekstrinsik yang berpengaruh terhadap kepuasan kerja karyawan pada Bank Muamalaat Indonesia Cabang Denpasar agar diperoleh gambaran yang lebih lengkap lagi

\section{DAFTAR RUJUKAN}

Hadari, Nawawi, dan Mimi Martini. 2009. Penelitian Terapan. Yogyakarta: Gajah Mada University Press

Karmita, Sagung Binda. 2015. "Pengaruh Motivasi Kerja dan penempatan karyawan terhadap kepuasan kerja dan kinerja karyawan". E-Jurnal Ekonomi Dan Bisnis Universitas Udayana, Vol. 4, No. 12.

Manullang M. 2001. Manajemen Sumber Daya Manusia. Yogyakarta: Andi Offset.

Maulana, Fakhrian Harza. 2015."Pengaruh Motivasi Instrinsik Dan Motivasi Ektrinsik Dan Komitmen Organisani Terhadap kinerja Karyawan". Jurnal Administrasi Bisnis, Vol 22, No. 1, Mei.

Noermijati. 2013. Aktualisasi Teori Herzberg, Kepuasan Kerja Dan Kinerja Spiritual Manajer Operasional. Malang: Universitas Brawijaya Press.

Noor, Juliansyah. 2013. Penelitian Ilmu Manajemen. Jakarta: KENCANA PRENADA MEDIA GROUP.

Siagian, Sondang P. 2004. Teori Motivasi Dan Aplikasinya. Jakarta: Rineka Cipta.

Siregar, Syofian. 2013. Statistic Parametrik Untuk Penelitian Kuantitatif, Jakarta: Bumi Aksara.

Sugiyono. 2008. Metode Penelitian Kuantitatif, Kualitatif dan $R \& D$. Bandung: Alfabeta.

Sugiyono. 2018. Metode Penelitian Kuantitatif. Bandung: Alfabeta.

Sutrisno, Edy. 2009. Manajemen Sumber Daya Manusia. Jakarta: PRENADA MEDIA Group. 